\begin{tabular}{|cc|}
\hline CIGARETTE & INDOOR \\
AUTOMOBILE & EXHAUST \\
BUTADIENE & ISOPRENE \\
BENZENE & ACETYLENE \\
ANALYSIS & EXPOSURE \\
\hline
\end{tabular}

Open access accepted manuscript version of

Journal of Chromatography 643 (1993) 71-76

doi:10.1016/0021-9673(93)80542-G

\title{
Assessment of ambient volatile hydrocarbons from tobacco smoke and from vehicle emissions
}

Gunnar Barrefors and Göran Petersson

Comparable analytical studies of specific hydrocarbons include:

Urban air near traffic

Road tunnels

Gasoline vapors 


\title{
ASSESSMENT OF AMBIENT VOLATILE HYDROCARBONS FROM TOBACCO SMOKE AND FROM VEHICLE EMISSIONS
}

\author{
Gunnar Barrefors and Göran Petersson* \\ Department of Chemical Environmental Science \\ Chalmers University of Technology \\ 41296 Göteborg, Sweden
}




\begin{abstract}
Quantitative proportions of $\mathrm{C}_{2}-\mathrm{C}_{8}$ alkenes, alkadienes, alkynes, alkanes and arenes were determined for indoor smoky air and for air inside a private car. Samples were taken on adsorbent cartridges and analyzed by gas chromatography on an $\mathrm{Al}_{2} \mathrm{O}_{3}$ column.

The proportions of more than twenty reported alkenes, alkadienes and alkynes were demonstrated to be very similar in a smoky room and in sidestream cigarette smoke. Isoprene, ethene and propene are major components. Urban air polluted by petrol-fuelled vehicles differs mainly by much lower proportions of isoprene and much higher proportions of petrol alkanes and alkylbenzenes. The total concentration of $\mathrm{C}_{2}-\mathrm{C}_{8}$ hydrocarbons was found to be similar in a smoky room and in a car in urban traffic.
\end{abstract}

\title{
INTRODUCTION
}

Increasing emphasis is given to health hazards from the well-known volatile hydrocarbons ethene [1], 1,3-butadiene [2], and benzene [3]. Other volatile alkenes, alkadienes and arenes are likely to constitute significant but less well-known hazards. The exposure of the non-smoking average person to these hydrocarbons is due mainly to environmental tobacco smoke and emissions from petrol-fuelled vehicles.

A few volatile hydrocarbons have been reported in a comprehensive experimental study [4] and in an overview [5] of environmental tobacco smoke. A recent study of in-vehicle air pollutants [6] was based on volatile petrol alkanes and arenes. The whole range of $C_{2}-C_{8}$ hydrocarbons from vehicles can be sampled on adsorbent cartridges and assessed by gas chromatography on a single column, as demonstrated recently for a road tunnel [7] and for urban air near to traffic [8]. This study demonstrates exposure-related applications of a similar technique to volatile hydrocarbons in environmental tobacco smoke as compared with vehicle-polluted urban air. A critical purpose of the study is to assess quantitative proportions for a wide range of the potentially hazardous $C_{2}-C_{8}$ hydrocarbons characterizing air polluted by the two differenat sources. 


\section{EXPERIMENTAL}

Several samples of environmental tobacco smoke were taken on different occasions in Junggrens Café, located along the parade avenue in Göteborg and well-known for its delicious sandwiches. The volume of the room is ca $150 \mathrm{~m}^{3}$ and about ten smoking and ten non-smoking guests were present during sampling. The absence of prominent contributions from room-specific sources in the café was ascertained by comparisons with samples from other smoky indoor places and with background samples taken before the opening of the café.

Sidestream cigarette smoke was obtained by dropping a lit cigarette into a $100 \mathrm{ml}$ glass vessel. Samples of gas were taken after two minutes. The volume of the glass vessel was not critical with respect to the resulting hydrocarbon composition. The commercial brands studied were Blend Ultima (Swedish) and Marlboro Light.

In-vehicle samples were taken in a private car, Nissan Micra 1988, with threeway catalyst equipment. The exhaust $\mathrm{CH}_{\mathrm{x}}$ level was well below $100 \mathrm{ppm}$ which is the upper limit permitted in the compulsory Swedish yearly car test. The fuel was unleaded RON 95 commercial petrol from the OK Petroleum chain. Samples were taken on two occasions during urban driving in Göteborg from Chalmers University of Technology to the Central Railway Station and back again. The driving time of 20 min included 10-20 stops at traffic lights and intersections. The engine was warm from start, the windows were closed, and the fan was set to intermediate speed. The ambient temperature was $10-20^{\circ} \mathrm{C}$ and the air was moderately turbulent. The absence of non-typical contributions to specific hydrocarbons was ascertained by comparisons with a variety of urban samples of trafficpolluted air.

Samples were taken on triple-layer cartridges (glass, $150 \mathrm{~mm} \times 4 \mathrm{~mm}$ i.d.) with Tenax TA (0.6 ml, 60/80 mesh, Chrompack), Carbotrap (0.4 ml, 20/40 mesh, Chrompack) and Carbosieve S-III (0.4 ml, 60/80 mesh, Chrompack) as adsorbents. The sampling volumes were $\sim 1 \mathrm{ml}$ for sidestream smoke and $\sim 500 \mathrm{ml}$ for ambient air. The analytical separations were performed on a $50 \mathrm{~m} \times 0,32$ mm i.d. fused silica PLOT column (Chrompack) with $\mathrm{AL}_{2} \mathrm{O}_{3} / 5 \% \mathrm{KCl}$ as the stationary phase. The system for sampling, thermal desorption and gas chromatography has been described previously [9]. The analytical results were checked with respect to the proportions of specific hydrocarbons by comparisons with duplicate samples. Ethene and the $\mathrm{C}_{3}$ hydrocarbons were sampled without breakthrough losses [9]. Alkadienes and the alkenes with more than two alkyl groups adjacent to 
the double bond appeared to be sensitive to losses by chemical decomposition when using the triple-layer cartridges. Their quantitative proportions were checked by duplicate samples taken on Tenax or Tenax + Carbotrap cartridges. Response differences of the flame ionization detector were disregarded although a correction for the somewhat higher response of benzene [7,8] and alkylbenzenes [7] was previously applied for urban air.

Mass spectra, total ion chromatograms and single ion chromatograms were obtained from a Varian Saturn II ion trap mass spectrometer, coupled to an $\mathrm{Al}_{2} \mathrm{O}_{3}$ column in the $\mathrm{GC}$ unit. Gas samples of side-stream cigarette smoke were injected directly on the GC-MS system without adsorbent sampling.

\section{RESULTS AND DISCUSSION}

\section{Chromatographic separation}

In Fig. 1, the separation achieved for $\mathrm{C}_{2}-\mathrm{C}_{8}$ hydrocarbons from a smoky café room is demonstrated. The identities of the hydrocarbons marked in the chromatogram were determined from retention data and from mass spectra of the corresponding species appearing in the chromatogram of sidestream cigarette smoke. A major advantage of the $\mathrm{Al}_{2} \mathrm{O}_{3}$ column is the clearcut position of $C_{n}$ alkenes between the $C_{n}$ and $C_{n+1}$ alkanes. The $C_{n}$ alkadienes elute later than the $\mathrm{C}_{\mathrm{n}}$ alkenes because of the larger induced polar interactions with the stationary phase. The nonlinear temperature program (Fig.1) further improved the separation of the hydrocarbons.

In studies of hydrocarbons, the $\mathrm{Al}_{2} \mathrm{O}_{3}$ column offers the advantage that polar compounds are not eluted from the column. The only oxygen-containing species observed from environmental tobacco smoke were furan and methylfurans. These are disregarded in the results given for hydrocarbons. Nitrogen-containing and other polar compounds from environmental tobacco smoke can be analyzed on conventional columns after proper adsorbent sampling [10].

\section{Hydrocarbon composition}

The quantitative proportions of prominent $\mathrm{C}_{2}-\mathrm{C}_{8}$ hydrocarbons are given in Table I with emphasis on a wide coverage of unsaturated species. Smoky ambient air is compared with sidestream smoke from a cigarette, with air inside a car during urban driving, and with vehicle- 


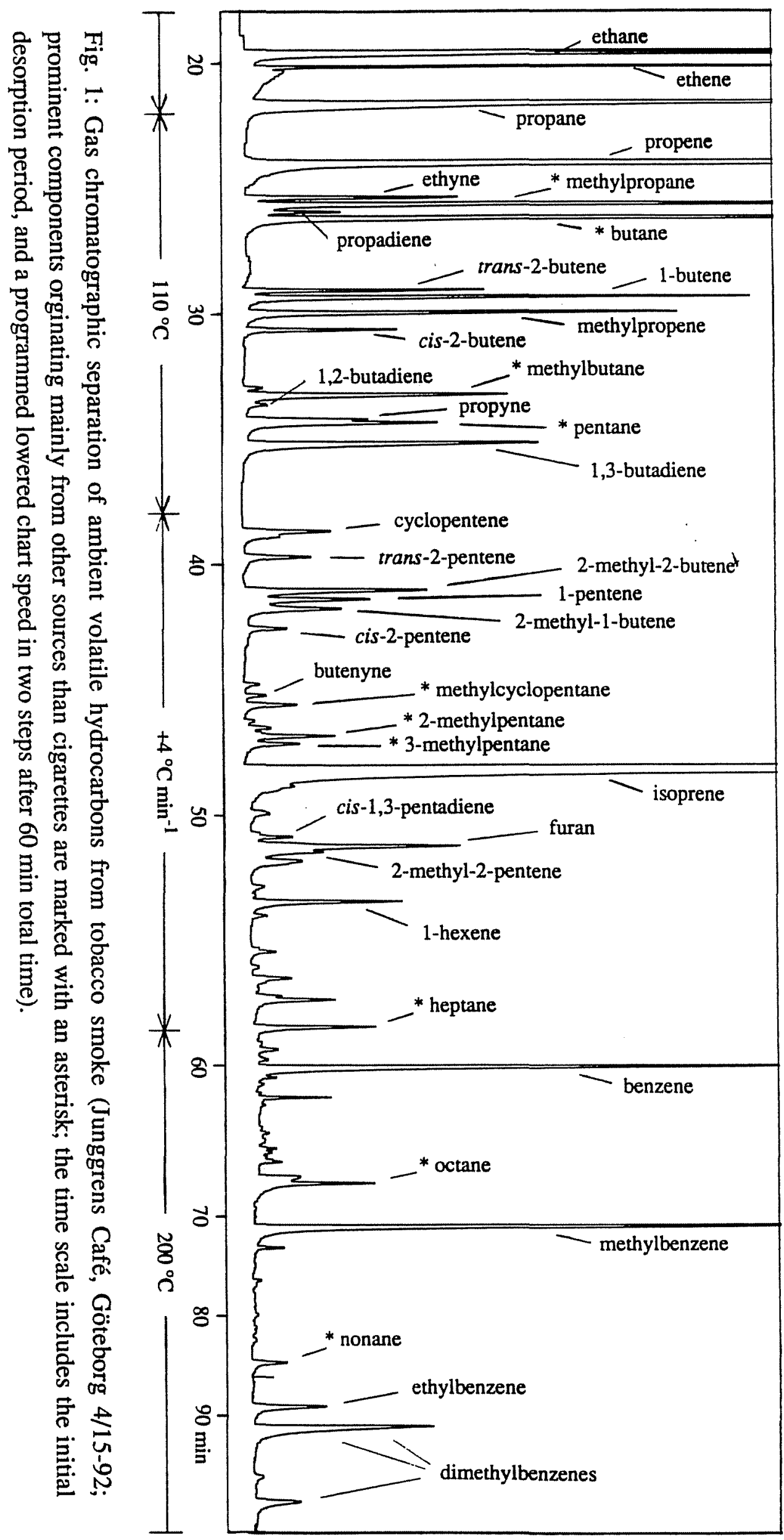


polluted air in a road tunnel.

The percent proportions of alkenes, alkadienes and alkynes are remarkably similar for the café and for the sidestream smoke. The proportion of the carcinogenic 1,3-butadiene is notably higher than in vehicle emissions. Isoprene (methyl-1,3-butadiene) is the major component in sharp contrast with vehicle-polluted air. The extensive release of isoprene is likely to be linked to the high content of linear isoprene polymers in tobacco [11]. The higher proportion of isoprene in sidestream smoke than in the smoky room may be due partly to a lower than average oxygen supply during the experimental combustion. The alkenes from tobacco and from vehicle emissions are the same, but their quantitative proportions are higher for tobacco smoke. Cigarette smoke contains ethene and propene in similar high amounts, whereas vehicles emit considerably more ethene than propene as combustion products. Among the isomeric $\mathrm{C}_{4}-\mathrm{C}_{6}$ alkenes, the proportions of unbranched 1alkenes and of 2-methyl-2-alkenes are relatively higher for cigarette smoke. The proportions of the 1,3-pentadienes and other incompletely resolved species were confirmed by mass spectrometric single-ion monitoring for sidestream smoke samples.

The proportions of alkylbenzenes and of $\mathrm{C}_{4}-\mathrm{C}_{8}$ alkanes are much higher in vehicle-polluted air than in cigarette smoke. These hydrocarbons are prominent components of petrol and are emitted mainly as unburnt exhaust hydrocarbons [8]. The volatile $\mathrm{C}_{4}-\mathrm{C}_{5}$ alkanes are also major components of petrol vapours. From the results given in Table $\mathrm{I}$, it is concluded that $\mathrm{C}_{4}-\mathrm{C}_{6}$ alkanes originate mainly from traffic emissions even in smoky rooms. Although there is little traffic near to the café, a significant contribution from vehicles is also indicated for benzene and the $\mathrm{C}_{7}$ $\mathrm{C}_{8}$ alkylbenzenes. Background samples taken before the opening of the cafe confirmed the presence of $\mathrm{C}_{4}-\mathrm{C}_{6}$ alkanes and $\mathrm{C}_{6}-\mathrm{C}_{8}$ arenes. On the other hand, the results for sidestream cigarette smoke demonstrate that not only benzene but also significant amounts of methylbenzene (toluene) and $\mathrm{C}_{8}$ alkylbenzenes are formed as combustion products from tobacco.

With regard to rooms polluted by cigarette smoking, it is concluded that alkadienes, alkenes and several other volatile hydrocarbons orginate predominantly from tobacco smoke. Mainstream smoke contributes although the yields are higher for sidestream smoke [5]. A comparison between sidestream and mainstream smoke indicated a similar composition for the $\mathrm{C}_{2}-\mathrm{C}_{8}$ hydrocarbons. $\mathrm{A}$ wide range of volatile hydrocarbons in mainstream smoke are known from early studies [12]. The hydrocarbon proportions in sidestream smoke from a Swedish cigarette (Blend) were found to be similar to those given in Table I (Marlboro). Sidestream smoke from different cigarettes is known 
TABLE I

COMPOSITION (\%) OF $\mathrm{C}_{2}-\mathrm{C}_{8}$ HYDROCARBONS IN AIR POLLUTED BY TOBACCO SMOKE AND TRAFFIC EMISSIONS.

\begin{tabular}{|c|c|c|c|c|c|}
\hline \multicolumn{2}{|c|}{. } & $\begin{array}{l}\text { Smoky } \\
\text { café } \\
4 / 15-92\end{array}$ & $\begin{array}{l}\text { Sidestream } \\
\text { smoke } \\
\text { Marlboro }\end{array}$ & $\begin{array}{c}\mathrm{Car} \\
9 / 23-92 \\
8.20-8.40\end{array}$ & $\begin{array}{c}\text { Road tunnel [7] } \\
2 / 19-92 \\
8.10-8.40\end{array}$ \\
\hline \multicolumn{2}{|c|}{ Alkenes } & 31 & 38 & 10 & 14 \\
\hline $\mathrm{C} 2$ & ethene & 8,9 & 11,1 & 4,7 & 7,8 \\
\hline C3 & propene & 11,6 & 9,6 & 2,3 & 2,8 \\
\hline \multirow[t]{4}{*}{ C4 } & trans-2-butene & 0,8 & 1,0 & 0,3 & 0,3 \\
\hline & 1-butene & 2,1 & 2,8 & 0,4 & 0,6 \\
\hline & methylpropene & 1,9 & 2,7 & 0,9 & 1,1 \\
\hline & cis-2-butene & 0,6 & 0,7 & 0,2 & 0,2 \\
\hline \multirow[t]{7}{*}{ C5 } & cyclopentene & 0,5 & 0,7 & 0,1 & 0,1 \\
\hline & 3-methyl-1-butene & 0,2 & 0,3 & 0,1 & 0,1 \\
\hline & trans-2-pentene & 0,3 & 0,4 & 0,2 & 0,2 \\
\hline & 2-methyl-2-butene & 1,2 & 2,7 & 0,3 & 0,3 \\
\hline & 1-pentene & 0,8 & 1,2 & 0,2 & 0,2 \\
\hline & 2-methyl-1-butene & 0,7 & 1,3 & 0,2 & 0,2 \\
\hline & cis-2-pentene & 0,2 & 0,3 & 0,1 & 0,1 \\
\hline \multirow[t]{2}{*}{ C6 } & 1-hexene & 0,8 & 1,3 & 0,1 & 0,1 \\
\hline & 2-methyl-2-pentene & 0,3 & 0,4 & 0,1 & 0,1 \\
\hline \multicolumn{2}{|c|}{ Alkadienes } & 20 & 34 & 2 & 1 \\
\hline C3 & propadiene & 0,2 & 0,2 & 0,1 & 0,2 \\
\hline \multirow[t]{2}{*}{$\mathrm{C} 4$} & 1,2-butadiene & 0,1 & 0,1 & 0,0 & 0,0 \\
\hline & 1,3-butadiene & 1,9 & 3,2 & 0,4 & 0,7 \\
\hline \multirow[t]{3}{*}{$\mathrm{C} 5$} & isoprene & 16,7 & 29,2 & 1,5 & 0,0 \\
\hline & cis-1,3-pentadiene & 0,2 & 0,2 & 0,0 & 0,0 \\
\hline & trans-1,3-pentadiene & 0,4 & 0,4 & 0,0 & 0,0 \\
\hline \multicolumn{2}{|c|}{ Alkynes } & 2 & 2 & 2 & 5 \\
\hline C2 & ethyne & 0,9 & 0,8 & 2 & 5 \\
\hline C3 & propyne & 0,4 & 0,4 & - & - \\
\hline $\mathrm{C} 4$ & butenyne & 0,1 & 0,2 & 0,0 & 0,0 \\
\hline \multicolumn{2}{|c|}{ Alkanes } & 28 & 12 & 46 & 35 \\
\hline $\mathrm{C} 2$ & ethane & 6 & 3 & 1,4 & 0,9 \\
\hline C3 & propane & 6 & 4 & 0,8 & 0,5 \\
\hline \multirow[t]{2}{*}{$\mathrm{C} 4$} & methylpropane & 4,0 & 0,5 & 5,1 & 2,8 \\
\hline & butane & 4,3 & 1,7 & 11,8 & 4,8 \\
\hline \multirow[t]{2}{*}{ C5 } & methylbutane & 1,5 & 0,3 & 9,1 & 7,1 \\
\hline & pentane & 1,1 & 0,5 & 3,3 & 3,2 \\
\hline \multirow[t]{4}{*}{ C6 } & methylcyclopentane & 0,3 & 0,0 & 2,0 & 1,8 \\
\hline & 2-methylpentane & 0,5 & 0,0 & 2,7 & 2,8 \\
\hline & 3-methylpentane & 0,3 & 0,0 & 2,0 & 2,4 \\
\hline & hexane & - & 0,0 & 2,2 & 2,0 \\
\hline \multicolumn{2}{|c|}{ Arenes } & 19 & 14 & 40 & 45 \\
\hline C6 & benzene & 4,8 & 3,9 & 9,6 & 9,1 \\
\hline C7 & methylbenzene & 8,4 & 6,4 & 16,0 & 17,5 \\
\hline \multirow{2}{*}{ C8 } & ethylbenzene & 1,0 & 0,7 & 3,1 & 3,7 \\
\hline & dimethylbenzenes & 4,3 & 2,8 & 11,6 & 14,5 \\
\hline
\end{tabular}


to differ less in composition than mainstream smoke [13]. The tabulated hydrocarbon proportions for sidestream smoke and smoky indoor air compare well with results previously reported for a few of the most prominent hydrocarbons [4]. Although the proportions of hydrocarbons were found to be similar in different smoky rooms, specific indoor sources and sinks may give partly deviating results.

With regard to in-vehicle volatile hydrocarbons, it is concluded that they orginate almost exclusively from traffic emissions. The results from the road tunnel represent outside-vehicle concentrations at low ambient temperature. The higher proportions of butanes in the private car may be due to petrol vapours from other vehicles and from the sampling car itself. The observed proportions of benzene and alkylbenzenes are higher than reported for US vehicles [6], because of the higher proportion of arenes in urban air in Sweden [8], reflecting a high content in petrol. The elevated concentration of isoprene in the car is likely to be explained by isoprene in exhaled air from the two persons in the car. The isoprene content in exhaled air may approach $1000 \mu \mathrm{g} / \mathrm{m}^{3}$ [14]. Differences in net human uptake between the hydrocarbons may also give rise to minor differences in concentrations. Thus benzene is known to be excreted through breath to a greater extent than alkylbenzenes [15].

\section{Human exposure}

In Table II, exposure levels for selected hazardous hydrocarbons are compared. The recorded concentrations are of the same order of magnitude in the smoky room as in the private car during urban driving. The alkene levels tend to be highest for cigarette smoke and the arene levels tend to be highest for traffic pollution. The café is regarded to be more smoky than average cafés but less smoky than many pubs. The lower in-vehicle level corresponds to moderate wind and traffic wheareas the upper level corresponds to weak wind and peak traffic. The upper in-vehicle concentrations were similar to those observed for volatile arenes in a recent study of hydrocarbons in commuter cars [16]. The road tunnel concentrations correspond to peak traffic and are 5-10 times higher than the in-vehicle levels. This is explained mainly by the limited dilution of the traffic emissions in the tunnel.

It was early demonstrated that the concentrations of traffic-emitted hydrocarbons are higher in private cars during urban driving than in the breathing zone of cyclists [17]. The concentrations in cars were also observed to be higher than on the pavement and several times higher than in off- 


\section{TABLE II}

CONCENTRATIONS $\left(\mu \mathrm{g} / \mathrm{m}^{3}\right)$ OF HAZARDOUS HYDROCARBONS IN A SMOKY ROOM AS COMPARED WTTH A PRIVATE CAR.

The first two samples represent high indoor levels of cigarette smoke, and the following two samples moderate and fairly high levels of vehicle-emitted pollutants inside a car during urban driving. The last column gives rush hour levels from previous measurements in an urban road tunnel [7].

\begin{tabular}{lccccc}
\hline & Café & Café & Car & Car & Tunnel \\
& $4 / 15-92$ & $5 / 12-92$ & $9 / 23-92$ & $9 / 24-92$ & $2 / 19-92$ \\
& $13.25-13.55$ & $10.30-11.00$ & $8.20-8.40$ & $7.50-8.10$ & $8.10-8.40$ \\
\hline $\mathbf{C H}_{\mathbf{x}}\left(\mathbf{C}_{\mathbf{2}}-\mathbf{C}_{\mathbf{8}}\right)$ & $\mathbf{6 4 0}$ & $\mathbf{5 7 0}$ & $\mathbf{3 9 0}$ & $\mathbf{6 3 0}$ & $\mathbf{3 6 0 0}$ \\
Ethene & 56 & 42 & 18 & 30 & 280 \\
Propene & 73 & 37 & 9 & 15 & 100 \\
Benzene & 30 & 38 & 37 & 55 & 330 \\
Methylbenzene & 53 & 40 & 62 & 110 & 630 \\
\hline
\end{tabular}


traffic places where official urban air pollution levels are often measured. Similar observations were made in a recent extensive study of in-vehicle air pollutants [6]. The obvious explanation is that cars run straight into air pollutants from the vehicles ahead, whereas the pollutants are rapidly diluted with increasing distance from the stream of vehicles.

It is evident that the concentrations of volatile hydrocarbons and other air pollutants are considerably higher in vehicles and in smoky rooms than in most other urban environments. The daily exposure time exceeds one hour for many people. Children are often exposed in vehicles and in public and private smoky rooms. It is concluded that exposure in smoky rooms and in vehicles should be primary targets in efforts to decrease health hazards due to urban volatile hydrocarbons. In Sweden, prohibition of smoking in hospitals and various public indoor environments are examples of means for reducing exposure. Current extensive plans for new urban road tunnels represent an environmental change which may cause severely increased exposure in vehicles [7].

\section{REFERENCES}

1 M. Törnqvist and L. Ehrenberg, LARC Sci. Publ., 104 (1990) 277.

2 J.E. Huff, R.L. Melnick, H.A. Solleveld, J. K. Haseman, M. Powers and R. A. Miller, Science, 227 (1985) 548.

3 A. Yardley-Jones, D. Anderson and D.V. Parke, Br. J. Ind. Med. 48 (1991) 437.

4 G. Löfroth, R.M. Burton, L. Forehand, S. K. Hammond, R.L. Seila, R. B. Zweidinger and J. Lewtas, Environ. Sci. Technol., 23 (1989) 610.

5 G. Löfroth, Mutation Res. 222 (1989) 73.

6 C.-C. Chan, H. Özkaynak, J. D. Spengler and L. Sheldon, Environ. Sci. Technol. 25 (1991) 964.

7 G. Barrefors and G. Petersson, Chemosphere 25 (1992) 691.

8 L. Löfgren and G. Petersson, Chemosphere, 24 (1992) 135.

9 L. Löfgren, P. M. Berglund, R. Nordlinder, G. Petersson and O. Ramnäs, Int. J. Environ. Anal. Chem. 45 (1991) 39.

10 D. L. Heavner, M. W. Ogden and P. R. Nelson, Environ. Sci. Technol. 26 (1992) 1737.

11 D. J. Eatough, L.D. Hansen and E. A. Lewis, Environ. Technol. 11 (1990) 1071. 
12 H. Elmenhorst and C. H. Schultz, Beitr. Tabaksforsch., 4 (1968) 90.

13 M. R. Guerin, C. E. Higgins and R. A. Jenkins, Atmos. Environ. 21 (1987) 291.

14 G. Löfroth, Excerpta Med. Intern. Congr. Ser. 860 (1989) 147.

15 L. A. Wallace, E. D. Pellizzari, T. D. Hartwell, C. M. Sparacino, L. S. Sheldon and H. Zelon, Atmos. Environ. 19 (1985) 1651.

16 L. Löfgren, K. Persson, A.-M. Strömvall and G. Petersson, Sci. Total Environ., 108 (1991) 225.

17 M. Mattsson and G. Petersson, Int. J. Environ. Anal. Chem. 11 (1982) 211. 